\title{
Development of a Catalytic Combustor with Thin-Honeycomb Substrate
}

\author{
Byungchul Choi ${ }^{1}$, Gyeongho Park ${ }^{2}$, Daeseok Kim ${ }^{2}$ \\ ${ }^{1}$ School of Mechanical Engin., Chonnam National University \\ 77 Yongbong-ro, Bug-gu, Gwangju, 61186, Republic of Korea, \\ ${ }^{2}$ Graduate Student of Depart. of Mechanical Engin., Chonnam National University \\ 77 Yongbong-ro, Bug-gu, Gwangju, 61186, Republic of Korea \\ Bcchoi@jnu.ac.kr
}

\section{Extended Abstract}

To obtain the most stable $\mathrm{H}_{2}$ yields in reforming systems, it is important to maintain a steady reaction temperature for catalytic reforming. When some parts of the catalytic combustor have hot spots with higher local temperatures, the combustor durability maybe affected or the reforming catalyst would be damaged, resulting in NOx generation [1]. Therefore, it is very important for a catalytic combustor that transfers heat into a reforming reactor to have a uniform temperature distribution.

Recently, many morphological studies on small-sized catalytic combustors, which are called microchannel catalytic combustors [2-5], have been conducted. A microchannel combustor has the advantage of higher mass transfer and higher surface area per volume. Kundu et al. reported sol of alumina and zirconia on the etched stainless steal micro-channel for steaming reforming of methanol produced better stability and performance [2], but the durability of catalyst was weak. The energy generated in the combustion channel was insufficient because of higher reaction temperature, so extra cartridge heaters provided extra heat. It is commonly very difficult to make a coating layer of catalysts for combustion and reforming reactions as micro-channels are made of metal or alumina materials. Particularly, catalysts coated on metal or on alumina are detached easily and have very low durability. After combustion or reforming, catalysts lose their activation energy and have to be replaced, resulting in high economic losses.

The objective this study is to optimize the catalytic combustor using a thin-honeycomb ceramic substrate, which is capable of providing a dimethyl ether (DME) reformer with a heat source required for endothermic reforming process. The catalytic combustor can also maintain a uniform temperature distribution about $500^{\circ} \mathrm{C}$. The catalytic combustor was set the type of a fixed-bed flow reactor under atmospheric pressure. $\mathrm{Pt} / \gamma-\mathrm{Al}_{2} \mathrm{O}_{3}$ catalyst was coated on the cordierite substrate (600 cpsi). The experimental variables are the composition of multi-catalyst blocks, flow distributor, space velocity, excess air ratio, exit cross-section ratio of the burner, and type of fuel.

From the results, it was found that the space velocity was selected at the range of $18,000-27,000 \mathrm{~h}^{-1}$ for stable combustion (RMSE(root mean square energy) <10). For the catalytic combustor using $\mathrm{C}_{3} \mathrm{H}_{8}$ as fuel, the design combination for the best performance with temperature uniformity and with no exhaust pollutants was the optimized Tshaped and $\mathrm{SiC}$ foam distributor, 3 catalyst blocks(lean coating on the front catalyst and rich coating on the rear of catalyst blocks), and 50\% minimum cross-section ratio of the combustor outlet. For the catalytic combustor fueled with DME, the temperature variation on the surface of the catalytic combustor could be maintained within $17.6^{\circ} \mathrm{C}$ compared to the reference temperature.

\section{Acknowledgements}

This work is financially supported by the Basic Research Lab (BRL) program (2015R1A4A1041746) funded by National Research Foundation of Korea. 


\section{References}

[1] J. Ahn, C. Eastwood, L. Sitzki, P. D. Ronney, "Gas-phase and catalytic combustion in heat-recirculating burners," in Proc. Combust Inst., 30, pp. 2463-2472, 2005.

[2] A. Kundu, J.M. Park, J.E. Ahn, S.S. Park, Y.G. Shul, H.S. Han, "Micro-channel reactor for steam reforming of methanol," Fuel, vol. 86, pp. 1331-1336, 2007.

[3] Y. Men, G. Kol, R. Zapf, H. Pennemann, V. Hessel, "Total combustion of propane in a catalytic microchannel combustor," Chem Engin Resear Desig., vol. 87, pp. 91-96, 2009.

[4] J. K. Jin, S. J. Kwon, "Fabrication and performance test of catalytic micro-combustors as a heat source of methanol steam reformer," Int J Hydrogen Energy, vol. 35, no. 4, pp. 1803-1811, 2010.

[5] A. Vigneault, J. R. Grace, "Hydrogen production in multi-channel membrane reactor via steam methane reforming and methane catalytic combustion," Int J Hydrogen Energy, vol. 40, pp. 233-243, 2015. 